\title{
AN UNEXPECTED REACTION OF A 3-AMINO-2H-AZIRINE WITH 1,3-BENZOXAZIN-2,4-DIONE
}

Chandrasekhar, B Parthasarathi ; Bieri, Jost H ; Heimgartner, Heinz

\begin{abstract}
The reaction of 3-dimethylamino-2,2-dimethyl-2H-azirine (1) with 1,3-benzoxazin-2,4-dione (3) in refluxing 2-propanol led not to the formation of a medium sized heterocycle but to the formation of the imidazo[2.1-b]-1,3-benzoxazin-5-one 4 and the imidazolin-2-one 5 in $33 \%$ and $74 \%$ yield, respectively. The structure of 4 has been confirmed by X-ray crystallographic analysis while 5 has been identified by comparison with an independently synthesized material (cf. Scheme 2). In Scheme 3 a reaction mechanism for the formation of 4 and 5 is suggested.
\end{abstract}

Posted at the Zurich Open Repository and Archive, University of Zurich

ZORA URL: https://doi.org/10.5167/uzh-97541

Journal Article

Published Version

Originally published at:

Chandrasekhar, B Parthasarathi; Bieri, Jost H; Heimgartner, Heinz (1982). AN UNEXPECTED REACTION OF A 3-AMINO-2H-AZIRINE WITH 1,3-BENZOXAZIN-2,4-DIONE. Heterocycles, 19:2079-2085. 
AN UNEXPECTED REACTION OF A 3-AMINO-2H-AZIRINE WITH

$$
1,3-B E N Z O X A Z I N-2,4-D I O N E
$$

B. Parthasarathi Chandrasekhar ${ }^{\text {a) }}$, Jost H. Bieri, and Heinz Heimgartner*

Organisch-chemisches Institut der Univers1tät zürich, winterthurerstrasse 190, CH-8057 Zürich, Switzerland

Gabriel Germain and Jean-Paul Declercq

Laboratoire de Chimie-Physique et de Cristallographie, Université de Louvain, Place L. Pasteur 1, B-1348 Louvain-la-Neuve, Belgium

Abstract - The reaction of 3-dimethylamino-2,2-dimethyl-2H-azirine (1) with 1,3-benzoxazin-2,4-dione (3) in refluxing 2-propanol led not to the formation of a medium sized heterocycle but to the formation of the imidazo[2,1-b]-1,3-benzoxazin-5-one $\underline{4}$ and the imidazolin-2-one $\underline{5}$ in 338 and 748 yield, respectively. The structure of $\underline{4}$ has been confirmed by $x$-ray crystallographic analysis while 5 has been identified by comparison with an independently synthesized material (cf. Scheme 2 ). In Scheme 3 a reaction mechanism for the formation of $\underline{4}$ and $\underline{5}$ is suggested.

During the last few years, we have studied some reactions of 3-amino-2H-azirines. These cyclic, three-membered amidines react with various proton-acidic compounds to give cyclic or noncyclic products ${ }^{1-2}$. Their formation has been explained via cleavage of the strained amidine ring, protonation of the azirine nitrogen being the first step in the reaction sequence. With some NH-acidic heterocycles, e.g., saccharine, phthalimide and 2,2-disubstituted malonimides, 3-dimethylamino2,2-dimethyl-2H-azirine (1) reacts to yield ring-expanded heterocyclic compounds

a) Present address: BASF India Limited, Maybaker House, S.K. Ahire Marg, Bombay 400 025, India. 
of type $\underline{2}$ with eight- and seven-membered rings, respectively ${ }^{3-4}$ (Scheme 1 ). A reaction mechanism involving the primary adduct a and the zwitterionic intermediate $\underline{b}$ is reasonable.

We have also trled to apply this reaction to the formation of products of type $\underline{2}$ containing nine ring members, starting with six-membered NH-acidic heterocycles. All reactions studied until now have not led to the desired ring expansion, although Scheme 1

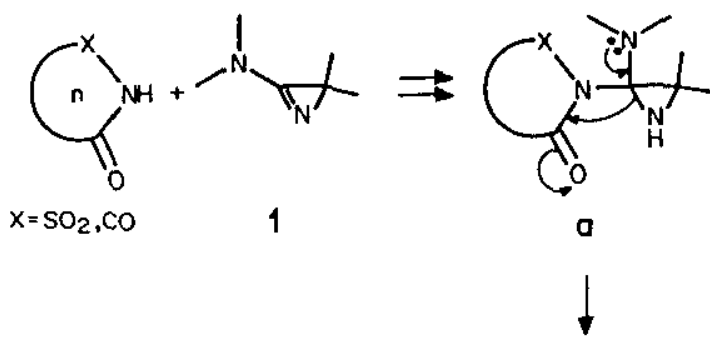

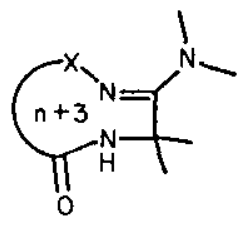

2

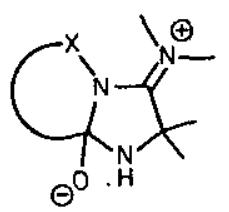

b

the zwitterionic intermediate $\underset{b}{b}$ seems to be formed ${ }^{2}$ (cf. also ${ }^{5-8}$ ). In the present paper, we wish to report the results of the reaction of 3-amino-2H-azirine 1 with 1,3-benzoxazin-2,4-dione (3) and the characterization of the products.

Refluxing a mixture of $448 \mathrm{mg}(4$ mmoles) of the azirine 1 and $326 \mathrm{mg}$ ( 2 mmoles) of the $\mathrm{NH}$-acidic heterocycle $\underline{3}$ in $20 \mathrm{ml}$ of acetonitrlle for 75 hours afforded two products $\underline{4}$ and $\underline{5}$ (Scheme 2 ). The reaction mixture was cooled and the solid material, identified as 4-dimethylamino-5,5-dimethyl-3-imidazolin-2-one (5) was separated by filtration. Thin layer chromatography $\left(\mathrm{Al}_{2} \mathrm{O}_{3}\right.$, benzene/chloroform) of the mother liquor afforded another portion of 5 , in addition to 2-dimethylamino-3,3dimethyl-10a-(2-propenyl)-3,10a-dihydro-imidazo $[2,1-b]-1,3-b e n z o x a z i n-5-o n e ~(4-)$. After recrystallization, the two products were isolated in yields of 748 ( $19 \mathrm{mp}$ $259-260^{\circ} \mathrm{C}$ from ethanol/ethyl acetate) and 338 (4, mp $177-178^{\circ} \mathrm{C}$ from dichloro- 
methane/hexane), respectively.

Scheme 2
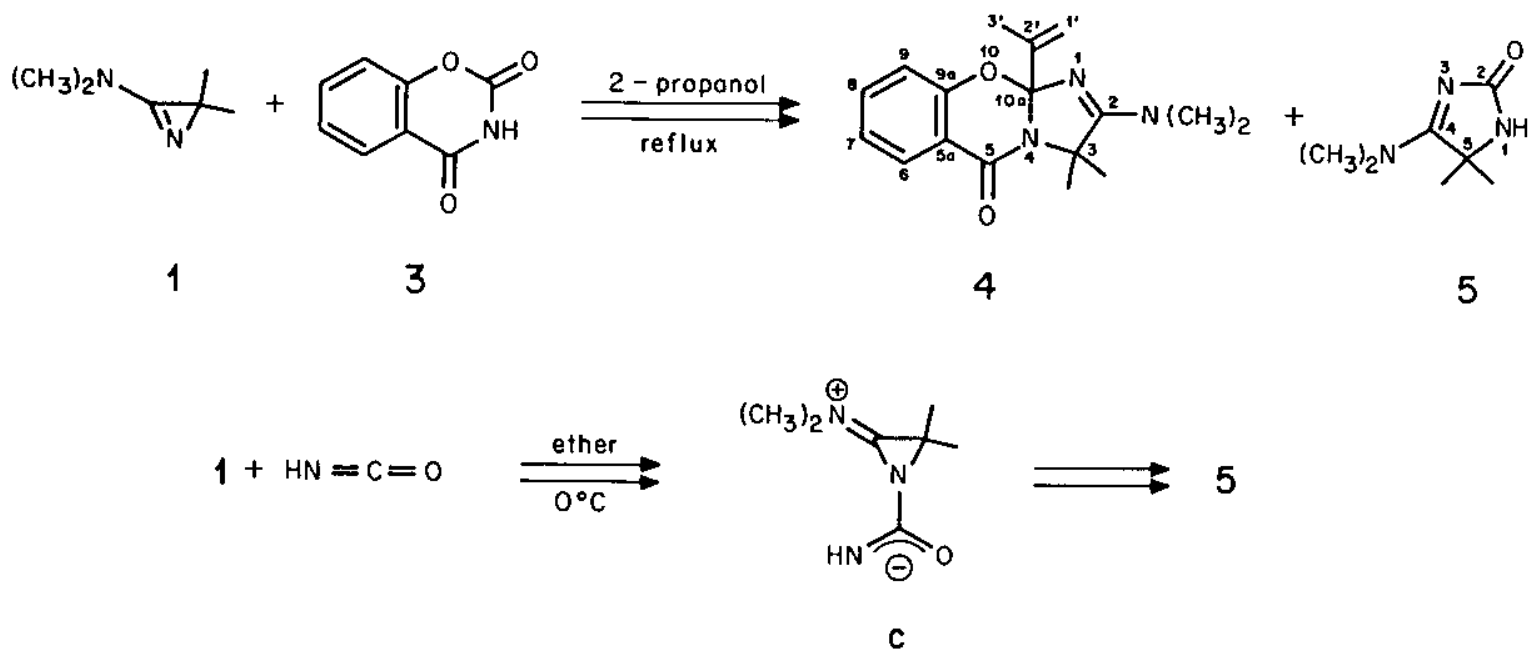

The structure of $\underline{5}$ has been deduced from elemental analysis ${ }^{9}$ and spectroscopic data 10. The material from the reaction of 1 and $\underline{3}$ was identical with an authentic reference, prepared from azirine 1 and isocyanic acid: Potassium isocyanate, suspended in ether at $-10^{\circ} \mathrm{C}$, was treated with cold sulfuric acid (cf. ${ }^{11}$ ), then the ethereal solution was added dropwise to a cold solution of azirine 1 in ether. Evaporation of the solvent and recrystallization of the residue from ethanol/ethyl acetate afforded $\underline{5}$ in 928 yield. ${ }^{12}$

Elemental analysis ${ }^{13}$ and spectroscopic data ${ }^{14}$ of the second reaction product $\underline{4}$ showed that it should be attributed to the reaction of $\underline{3}$ and two moles of azirine 1 , as suggested by the presence of a geminal dimethyl group and an isopropenyl group. The spectroscopic data suggested structure $\underline{4}$ but were not unambiguous. Therefore, an $\mathrm{X}$-ray crystallographic analysis was undertaken on colourless single crystals obtained from $\mathrm{CH}_{2} \mathrm{Cl}_{2}$ /hexane.

The new heterocyclic compound $\underline{4}$ crystallizes in the triclinic space group $P \overline{1}$ with $a=14.552(4), b=14.083(4), c=8.982$ (4) $\AA ; \alpha=77.19$ (3), $\beta=106.17$ (3), $\gamma=112.42(2)^{\circ}$ and $z=4$. The intensities of 4794 independent reflexions were measured with monochromatized $\mathrm{MoK}_{\alpha}$ radiation on a Syntex $\mathrm{P} 2$, automatic four-circle 
diffractometer in the range $3^{\circ}<20<47^{\circ}(\omega-$ scan). The structure was solved by direct methods using the computer programs MULTAN-78 ${ }^{15}$ and SHELX-76. 16 In the least squares refinement all $\mathrm{C}-, \mathrm{N}-$ and O-atoms were refined anisotropically while the attached $\mathrm{H}$-atoms were allowed to ride upon them with the common isotropic temperature factors after calculation of their positions. The final R-value is 0.056 for 3755 observed reflexions with $I \geq 2.5 \sigma(I)$.

Figure 1 shows the molecular structure of the reaction product $\underline{4}$.
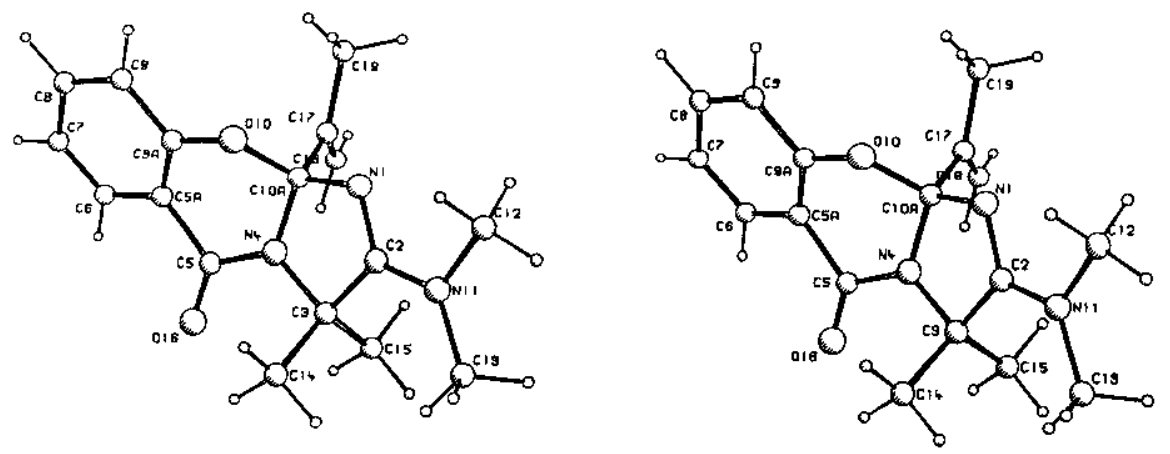

Fig. 1. Stereoscopic projection of the imidazo[2,1-b]-1,3-benzoxazin-5-one derivative $\underline{4}$

A plausible reaction mechanism for the formation of the products $\underline{4}$ and $\underline{5}$ is postulated in Scheme 3. Protonation of the azirine by the NH-acidic heterocycle $\underline{3}$ and nucleophilic attack of the anion to the amidinium c-atom leads to the aziridine $\underline{\text {, }}$ which rearranges to yield the zwitterionic intermediate $\underline{e}$. This zwitterion avoids breaking the central $\mathrm{C}-\mathrm{N}$ bond to give a medlum sized heterocycle (cf. Scheme 1), and is converted to the rearranged intermediate $\mathrm{g}$. A fragmentation as indicated in Scheme 3 leads to the benzoxazinone $\underline{h}$ and isocyanic acid. The latter reacts quite readily (cf. Scheme 2) with aminoazirine 1 yielding the imidazolin-2-one 5 . Formation of the second product $\underline{4}$ can be rationalized from $\underline{h}$ via nucleophilic attack of a third molecule of aminoazirine $\underline{i}$ to give $\underline{i}$, followed by cleavage of the threemembered ring to the 1-aza-allyl-cation $\underline{k}$ and ring closure. All the different ring 


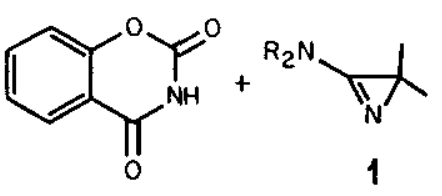

3<smiles></smiles>

d

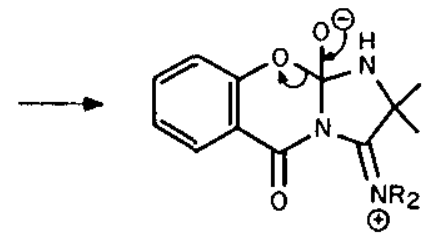

e

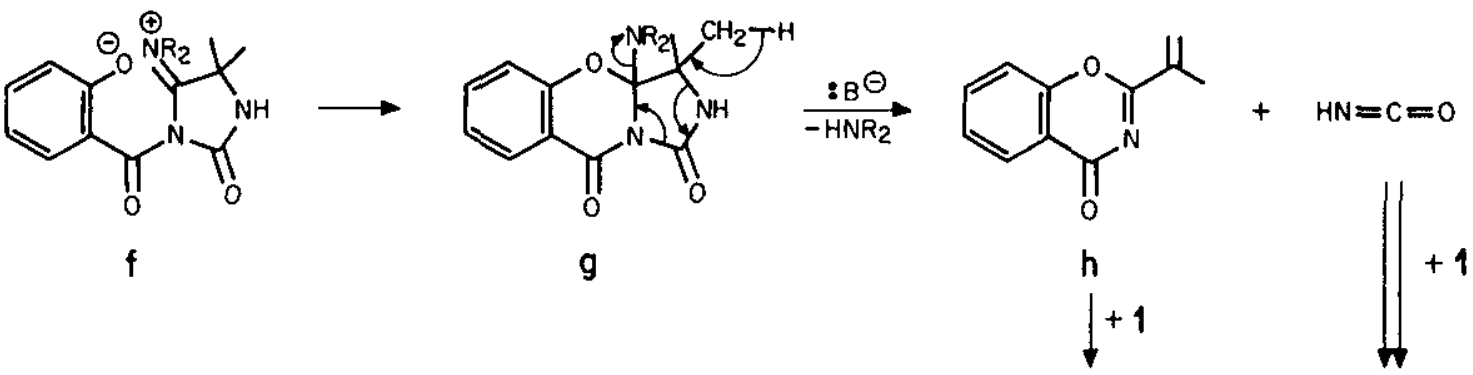<smiles>C=C(C)C12N=C(N[R2]CC)C(C)(C)N1C(=O)c1ccccc1O2</smiles>

4<smiles></smiles>

k<smiles>[R20]=C1N(C2(C(=C)C)NC(=O)c3ccccc3O2)C1(C)C</smiles>

i<smiles>[R20]n1[nH]c(=O)[nH]c1=O</smiles>

5

opening processes of the aminoazirine moiety suggested in scheme 3 are formulated in analogy to known reactions (cf. ${ }^{1}$ ).

ACKNOWLEDGEMENTS. The support of this work by the Swiss National Science Foundation and by F. Hoffmann-La Roche \& Co. AG, Basel, is gratefully acknowledged.

REFERENCES AND NOTES

1 H. Heimgartner, Chimia, 33, 111 (1979).

2 H. Heimgartner, Israel J. Chem., 21, 151 (1981).

3 S. Chaloupka, P. Vittorelli, H. Heimgartner, H. Schmid, H. Link, K. Bernauer, and W.E. Oberhänsii, Eelv. Chim. Acta, 60, 2476 (1977).

4 B. Scholl, J.H. Bieri, and H. Heimgartner, Helv. Chim. Acta, 61, 3050 (1978).

5 H. Link, K. Bernauer, S. Chaloupka, H. Heimgartner, and H. Schmid, Helv. Chim. $\underline{\text { Acta }}, \underline{61}, 2116(1978)$.

6 G. Mukherjee-Müller, S. Chaloupka, H. Heimgartner, H. Schmid, H. Link, K. Bernauer, P. Schönholzer, and J.J. Daly, Helv. Chim. Acta, 62,768 (1979). 
7 H. Link, K. Bernauer, J.J. Daly, S. Chaloupka, and H. Heimgartner, Helv. Chim. Acta, 64, 49 (1981).

8 M. Dähler, R. Prewo, J.H. Bieri, and H. Heimgartnex, Helv. Chim. Acta, In press.

9 5: $\mathrm{C}_{7} \mathrm{H}_{13} \mathrm{~N}_{3} \mathrm{O}(155.20)$; calculated: C $54.17 \mathrm{H} 8.44 \mathrm{~N} 27.078$; found: $\mathrm{C} 54.44$ H 8.23 N 26.918 .

10 : uv (ethanol): $\lambda \max 246.3 \mathrm{~nm}(\log \varepsilon=4.04) ;$ ir $(\mathrm{KBr}): 1695 \mathrm{~s}(\mathrm{C}=0), 1593 \mathrm{~s}$ $(\mathrm{C}=\mathrm{N}), 1409 \mathrm{~m}, 1310 \mathrm{~s}$, and $903 \mathrm{~s} \mathrm{~cm}^{-1} ;{ }^{1} \mathrm{H}-\mathrm{nmr}\left(\mathrm{CD}_{2} \mathrm{Cl}_{2}\right): 6.2$ (broad $\left.\mathrm{s}, \mathrm{NH}\right), 3.13$ (s, $\left.\left(\mathrm{CH}_{3}\right){ }_{2} \mathrm{~N}\right), 1.52 \mathrm{ppm}\left(\mathrm{s},\left(\mathrm{CH}_{3}\right){ }_{2} \mathrm{C}\right) ;{ }^{13} \mathrm{C}-\mathrm{nmr}\left(\mathrm{CD}_{3} \mathrm{OD}\right): 183.6$ (s, $\left.\mathrm{C}(4)\right), 169.4$ (s, $\mathrm{C}(2)), 62.6(\mathrm{~s}, \mathrm{C}(5)), 40.5$ and $39.5\left(2\right.$ broad signals, $\left(\mathrm{CH}_{3}\right) 2^{\mathrm{N}}$; at $60^{\circ} \mathrm{C}$ : qa at $39.9), 24.9 \mathrm{ppm}\left(\mathrm{qa},\left(\mathrm{CH}_{3}\right){ }_{2} \mathrm{C}\right)$; ms: $155\left(\mathrm{M}^{+}, 39\right), 154(76), 140(25), 111(11)$, $99\left(\mathrm{C}_{4} \mathrm{H}_{7} \mathrm{~N}_{2} \mathrm{O}, 39\right), 98(12), 97(10), 83(21), 71\left(\mathrm{C}_{3} \mathrm{H}_{7} \mathrm{~N}_{2}, 100\right), 70\left(\mathrm{C}_{3} \mathrm{H}_{6} \mathrm{~N}_{2}, 95\right)$, $69(20), 56(16), 44(34), 43(11), 42(79), 41(22)$.

11 Cf. H.P. Kaufmann and F. Kögler, Ber., 58, 1553 (1925); H. Lecher and F. Graf, ibid. , 59, 2601 (1926).

12 A very similar reaction has been observed with aminoazirine 1 and thiocyanic acid, leading to 4-dimethylamino-5,5-dimethyl-3-imidazolin-2-thione: $S$. Chaloupka, H. Heingartner, H. Schmid, H. Link, P. Schönholzer, and K. Bernauer, Helv. Chim. Acta, $\underline{59}, 2566$ (1976).

13 4: $\mathrm{C}_{17} \mathrm{H}_{21} \mathrm{~N}_{3} \mathrm{O}_{2}(299.37)$; calculated: C $68.20 \mathrm{H} 7.07 \mathrm{~N} 14.048$; found: C 68.26 H 7.15 N 14.008; osmometric molecular weight determination $\left(\mathrm{CHCl}_{3}\right)$ : found 281 . 14 는 uv (ethanol): $\lambda \max 300(\log \varepsilon=3.25), 232 \mathrm{~nm}(\log \varepsilon=4.39) ;$ ir (KBr): $1668 \mathrm{~s}(\mathrm{C}=0), 1600 \mathrm{~s}(\mathrm{C}=\mathrm{N}), 1582 \mathrm{~m}, 1468 \mathrm{~s}, 1390 \mathrm{~s}, 1280 \mathrm{~m}, 1245 \mathrm{~m}, 1230 \mathrm{~m}, 1213 \mathrm{~m}, 1165 \mathrm{~s}$, $1142 \mathrm{~m}$, and $1120 \mathrm{~m} \mathrm{~cm}^{-1} ;{ }^{1} \mathrm{H}-\mathrm{nmx}\left(\mathrm{CDCl}_{3}\right): 8.0-7.7(\mathrm{~m}, 1$ arom. $\mathrm{H}), 7.6-6.8$ (m, 3 arom. H), 5.00 and $4.90\left(2 \mathrm{~m},=\mathrm{CH}_{2}\right), 3.08\left(\mathrm{~s},\left(\mathrm{CH}_{3}\right)_{2} \mathrm{~N}\right), 1.88$ and $1.85 \mathrm{ppm}(2 \mathrm{~s}$, $\left.\left(\mathrm{CH}_{3}\right){ }_{2} \mathrm{C}\right) ;{ }^{13} \mathrm{C}-\mathrm{nmr}\left(\mathrm{CDCl}_{3}\right): 169.4$ (s, C(5)), 160.3 (s, C(2)), 154.7 (s, C(9a)), 144.7 (s, $\left.C\left(2^{\prime}\right)\right), 133.7,127.1,121.7$, and $116.9(4 \mathrm{~d}, \mathrm{C}(6)-\mathrm{c}(9)), 120.7$ (s, $\mathrm{C}(5 \mathrm{a})), 113.5\left(\mathrm{t}, \mathrm{C}\left(1^{\prime}\right)\right), 110.2(\mathrm{~s}, \mathrm{C}(10 \mathrm{a})), 67.1(\mathrm{~s}, \mathrm{C}(3)), 39.0\left(\mathrm{qa},\left(\mathrm{CH}_{3}\right) 2^{\mathrm{N}}\right)$,

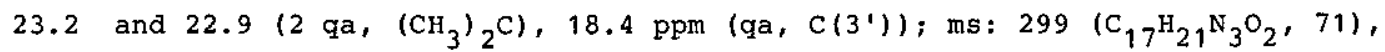
$284\left(\mathrm{C}_{16} \mathrm{H}_{18} \mathrm{~N}_{3} \mathrm{O}_{2}, 43\right), 270\left(\mathrm{C}_{16} \mathrm{H}_{20} \mathrm{~N}_{3} \mathrm{O}, 28\right), 258\left(\mathrm{C}_{14} \mathrm{H}_{16} \mathrm{~N}_{3} \mathrm{O}_{2}, 50\right), 256\left(\mathrm{C}_{15} \mathrm{H}_{18} \mathrm{~N}_{3} \mathrm{O}\right.$, $50), 254\left(\mathrm{C}_{16} \mathrm{H}_{20} \mathrm{~N}_{3}, 52\right), 179\left(\mathrm{C}_{10} \mathrm{H}_{17} \mathrm{~N}_{3}, 25\right), 164\left(\mathrm{C}_{9} \mathrm{H}_{14} \mathrm{~N}_{3}, 26\right), 109\left(\mathrm{C}_{7} \mathrm{H}_{11} \mathrm{~N}^{\mathrm{N}}\right.$ $100), 68(66), 44(35), 42(23), 41(21), 40$ (14). 
15 P. Main, S.E. Hull, L. Lessinger, G. Germain, J.-P. Declercq, and M.M. Woolfson, MULTAN-78, A system of Computer Program for the Automatic Solution of Crystal Structures from X-Ray Diffraction Data, York, U.K. and Louvain-la-Neuve, Belgium, 1978.

16 G.M. Sheldrick, SHELX-76, Program for Crystal Structure Determination, University of Cambridge, U.K., 1976.

Received, 28th July, 1982 